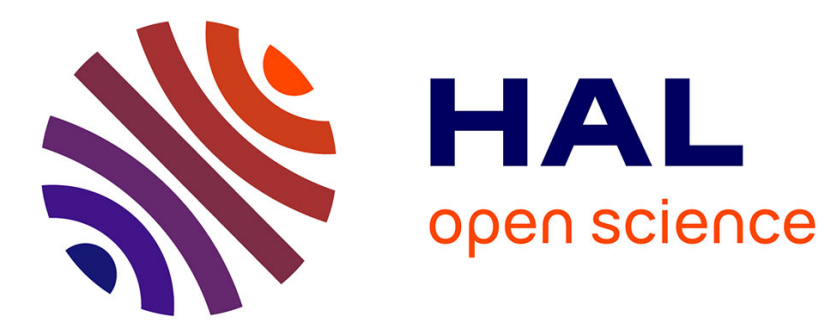

\title{
The distribution of the recessus orbitalis across flatfishes (order: Pleuronectiformes)
}

Matthew Campbell, Pakorn Tongboonkua, Bruno Chanet, Wei-Jen Chen

\section{To cite this version:}

Matthew Campbell, Pakorn Tongboonkua, Bruno Chanet, Wei-Jen Chen. The distribution of the recessus orbitalis across flatfishes (order: Pleuronectiformes). Journal of Fish Biology, 2020, 10.1111/jfb.14356 . hal-02877196

\section{HAL Id: hal-02877196 https://hal.sorbonne-universite.fr/hal-02877196}

Submitted on 22 Jun 2020

HAL is a multi-disciplinary open access archive for the deposit and dissemination of scientific research documents, whether they are published or not. The documents may come from teaching and research institutions in France or abroad, or from public or private research centers.
L'archive ouverte pluridisciplinaire HAL, est destinée au dépôt et à la diffusion de documents scientifiques de niveau recherche, publiés ou non, émanant des établissements d'enseignement et de recherche français ou étrangers, des laboratoires publics ou privés. 
See discussions, stats, and author profiles for this publication at: https://www.researchgate.net/publication/340927798

\section{The distribution of the recessus orbitalis across flatfishes (order:} Pleuronectiformes)

Article in Journal of Fish Biology · April 2020

DOI: $10.1111 /$ ffb. 14356

CITATIONS

0

4 authors:

Matthew Campbell

University of Alaska Museum

49 PUBLICATIONS 650 CITATIONS

SEE PROFILE

Bruno Chanet

Muséum National d'Histoire Naturelle

85 PUBLICATIONS 614 CITATIONS

SEE PROFILE
5

8 Pakorn Tongboonkua

National Taiwan University

5 PUBlications 1 Citation

SEE PROFILE

1. Wei-Jen Chen

National Taiwan University

111 PUBLICATIONS 2,822 CITATIONS

SEE PROFILE

Some of the authors of this publication are also working on these related projects:

Testing the significance of the Sunda Shelf barrier to the evolution of marine fishes in Indo-Malayan realm View project

Anatomy of soft organs in teleostean fishes View project 


\title{
The distribution of the recessus orbitalis across flatfishes (order: Pleuronectiformes)
}

\author{
MATTHeW A. CAMPBell ${ }^{1}$
}

PAKORN TONGBOONKUA ${ }^{1}$

BRUNO CHANET ${ }^{2, *}$

WEI-JEN CHEN ${ }^{1, *}$

${ }^{1}$ Institute of Oceanography, National Taiwan University, Taipei, Taiwan

${ }^{2}$ Institut de systématique, évolution, biodiversité (ISYEB), Sorbonne Université, Paris, France

\section{*Co-Corresponding Authors}

Wei-Jen Chen

wjchen.actinops@gmail.com,

Room 301, Institute of Oceanography, National Taiwan University,

No.1 Sec. 4 Roosevelt Rd., Taipei 10617, Taiwan

Phone: 886 (0)2-3366-1630; 886 (0)2-2363-6040 ext.301 Fax: 886 (0)2-2363-7062

Bruno Chanet

chanet@mnhn.fr

Équipe Homologies. Institut de systématique, évolution, biodiversité (ISYEB), Sorbonne

Université, MNHN, CNRS, EPHE. CP 30, 57 Rue Cuvier, 75005 Paris, France.

This article has been accepted for publication and undergone full peer review but has not been through the copyediting, typesetting, pagination and proofreading process which may lead to differences between this version and the Version of Record. Please cite this article as doi: $10.1111 / \mathrm{jfb} .14356$. 


\begin{abstract}
The recessus orbitalis is an accessory organ of flatfishes functioning in the protrusion of the eyes. This character along with cranial asymmetry and a forward insertion of the dorsal fin have been considered synapomorphies for the Pleuronectiformes. New dissections and examination of images taken in the wild show that the recessus orbitalis is present in all representatives of Pleuronectoidei examined, but is absent in the single species of Psettoidei dissected. Psettoidei, the most primitive pleuronectiform taxon, contains three recognized species; thus the absence of the recessus orbitalis in this lineage is unclear without further dissections. Ancestral character estimation at the family-level for the recessus orbitalis indicates that the recessus orbitalis was likely absent in the common ancestor of Pleuronectiformes, but was most likely present in the common ancestor of the Pleuronectoidei. Given that so few species of flatfishes have been assessed for the recessus orbitalis to date, additional characterization of the distribution of the recessus orbitalis across flatfishes will further inform what states this character may have and if it is a synapomorphy of Pleuronectiformes or simply a derived character-state of Pleuronectoidei.
\end{abstract}

Key Words: Pleuronectoidei; Phylogenetics; Psettoidei; Psettodes

\title{
Significance Statement
}

Flatfish monophyly has been supported anatomically by three synapomorphies. One of these is the recessus orbitalis, an accessory organ that aids in the protrusion of the eyes. It has been considered to present across all flatfishes (Pleuronectiformes) but previously only assessed in three families. Here we present the first description of this accessory organ from flatfishes in over 100 years demonstrating its broad occurrence in Pleuronectoidei and conspicuous absence in Psettoidei. Our results from Psettoidei are based on a single species, requiring further dissections to conclude on the presence of the recessus orbitalis in Psettoidei and consequently on recessus orbitalis as a pleuronectiform synapomorphy. 
Flatfishes, by possessing cranial asymmetry, are atypical among vertebrates and are classically considered to belong to a single order, Pleuronectiformes (Norman, 1934; Chapleau, 1993; Munroe, 2005). Cranial asymmetry associated with ocular migration is one of three synapomorphies proposed by Chapleau (1993) in support of monophyly of the Pleuronectiformes along with an advanced position of the dorsal fin over the cranium and the presence of a recessus orbitalis.

The recessus orbitalis is a muscular sac-like evagination localized in the posterior side of the orbit in some flatfishes. This organ has been demonstrated to be involved in the protrusion of the eyes above the body surface (Fig. 1A) (Holt, 1894). This ability is essential to flatfish species when buried in the substrate as it allows the fish to project its eyes above the material camouflaging the body, thus maintaining sight e.g. (Cole and Johnstone, 1902; Norman, 1934). Consequently, the recessus orbitalis is considered an accessory organ helping vision by Holt (1894). This author described this structure in several pleuronectid species, one scophthalmid and one soleid (Fig. 1B, Table 1). Several years later, Cole and Johnstone (1902) described the recessus orbitalis in detail in the plaice, Pleuronectes platessa L. 1758 (Pleuronectidae). Since Holt (1894) and Cole and Johnstone (1902) no direct observations of the recessus orbitalis have been described in the literature.

The seminal work of Chapleau (1993) conducted a thorough cladistic analysis of flatfishes and recognized the need for additional study of the recessus orbitalis given the very limited documentation to date (Table 1). Nevertheless, Chapleau (1993) considered the presence of this organ as a synapomorphy supporting the monophyly of the Pleuronectiformes. However, Chabanaud (1937) remarked that the most primitive flatfish family, Psettodidae, constituting one of the two flatfish suborders and consisting of a single genus Psettodes e.g. (Norman, 1934; Chapleau, 1993; Munroe, 2005), are not capable of protruding their eyes. This observation of Chabanaud (1937) based on two of the three recognized species of Psettodes suggests that the recessus orbitalis is absent in the species of this family. Since Chapleau (1993), authors have pointed out that the distribution of the recessus orbitalis has not been determined wholly across pleuronectiform fishes and may not be present in Psettodes (Chanet et al., 2020; Campbell et al., 2013). Chanet et al. (2020) concluded that the presence of this organ cannot be used to define the pleuronectiform order as a clade and that further work should be dedicated to the anatomy and the distribution of the recessus orbitalis conducted on fresh specimens. The present study shows the results of dissections of the orbital region in 
various flatfish species, Psettodidae included, reaffirming the existence of and describing the taxonomic distribution of the recessus orbitalis.

All fish specimens examined by the authors were obtained from fish markets and were not collected as part of faunal surveys. The care and use of experimental animals complied with Taiwanese animal welfare laws, guidelines and policies as approved by the National Taiwan University. This project did not involve experiments on live fishes nor the handling of any live fishes. The orbital region of fish specimens was dissected following the protocol described by Holt (1894) with examined taxa described in Supplemental Document S1: Psettodidae, Psettodes erumei (Bloch \& Schneider 1801); Bothidae, Arnoglossus yamanakai Fukui, Yamada, \& Ozawa 1988, Chascanopsetta lugubris Alcock 1894; Citharidae, Brachypleura novaezeelandiae Günther 1862 ; Cynoglossidae, Cynoglossus ochiaii Yokogawa, Endo, \& Sakaji 2008; Paralichthyidae, Pseudorhombus levisquamis (Oshima 1927); Poecilopsettidae, Poecilopsetta plinthus (Jordan \& Starks 1904); Samaridae, Samariscus latus Matsubara \& Takamuki 1951; Soleidae Aseraggodes kobensis (Steindachner 1896); and Pegusa lascaris (Risso 1810) (N. Schnell, personal communication). To further evaluate the distribution of the recessus orbitalis across pleuronectiforms, we examined photos of flatfishes in their natural environments (Supplemental Document S2).

The recessus orbitalis is absent in both left-eyed and right-eyed Psettodes erumei (Fig. 1C \& 1D), but was present in all pleuronectoids examined (Fig. 1E \& 1F, Table 1, Supplemental Document S2, and Data Supplement). In Psettodes, the skinning of the orbital region shows only the adductor mandibulae muscle and no other structure (Burgin, 1989). While in each examined pleuronectoid taxon, a sac-like structure is present, i.e. the recessus orbitalis, immediately behind the bulb (Fig. 1E \& 1F). Anatomical observations from seven pleuronectoid families in this study have been complemented by the examination of photographs taken in the wild for various species (Supplemental Document S2). In these species, extruded eyes can be observed and we interpret this ability as revealing the existence the recessus orbitalis. The presence of the recessus orbitalis has now been indirectly or directly observed in 12 pleuronectoid families: the single family of Citharoidea, all five families in the Pleuronectoidea, and six families in the Soleioidea (Figure 2).

The recessus orbitalis has been directly observed, see Table 1, in Bothidae, two species (this study), Citharidae, one species (this study, Fig. 1F), Cynoglossidae, one species (this study), 
in Paralichthyidae, one species, (this study, Fig. 1E), in Pleuronectidae, six species (Holt, 1894; Cole and Johnstone, 1902), in Poecilopsettidae, one species (this study), in Samaridae, one species (this study), in Scophthalmidae, one species (Holt, 1894) and in Soleidae, three species (this study; Holt (1894)). Moreover, the presence of this organ has been deduced in 27 species and three additional families: the Achiridae, the Cyclopsettidae, and the Rhombosoleidae (Supplemental Document S2). But, this organ is absent in Psettodes erumei (this study, Fig. 1C \& 1D). The latter observation is confirmed by the study of myology of the cephalic region of Psettodes erumei (Burgin, 1989).

Is the recessus orbitalis a synapomorphy of the Pleuronectiformes? Given the available data, we conducted ancestral character estimation of the recessus orbitalis with the package ape version 5.3 in R version 3.6.1 (Paradis and Schliep, 2018). To do so, we created a family-level phylogeny of Pleuronectiformes by pruning the maximum likelihood phylogeny from Campbell et al. (2019) to a single representative of each flatfish family as well as the outgroup family Centropomidae. The recessus orbitalis for a family was considered present if a single species in that family either through dissection or photographs was indicated to have the recessus orbitalis (Figure 2). Of all flatfish examined, only Psettodes erumei has direct evidence for the absence of the recessus orbitalis. Absence of this character in Psettodes belcheri Bennet 1831 is supported by indirect observation (Chabanaud, 1937); therefore, Psettodidae and the outgroup family (Centropomidae) were considered to not have the recessus orbitalis. We then conducted squared-change parsimony ancestral character estimation. The probability of the recessus orbitalis being present in the common ancestor of all pleuronectiforms was 0.07 and for the common ancestor of pleuronectoids was 0.96 (Figure 2).

The ancestral character estimation conducted at the family-level highlights the need for future examinations of pleuronectoids as so few species out of the total pleuronectiform diversity have been directly assessed for the presence or absence of the recessus orbitalis $(17$ / >800). In addition to characterizing the known distribution of this character, the examination of more pleuronectiform species can answer if secondary loss of the recessus orbitalis has occurred and if there is variation in the physical form of the recessus orbitalis itself. Our efforts were widespread and examined representatives from all three pleuronectoid superfamilies including the earliest-branching superfamily of pleuronectoids, Citharoidea. The six species within 
Citharoidea have been more recently accepted into a single family, Citharidae. Citharids possess unique anatomical features for pleuronectoids often considered primitive, such as a spine in the pelvic fin, separated gill membranes and vomerine teeth (Hoshino, 2001). Although the Citharoidea has several primitive flatfish characteristics, it does appear to possess the recessus orbitalis based on direct evidence from a single species. The evidence gathered for both Citharoidea and Psettoidei for the presence or absence of the recessus orbitalis is based on a single species from each group, and limits conclusions that can be drawn regarding the recessus orbitalis in these taxa. Establishment of the presence or absence of this trait more broadly across the Citharoidea in addition to all three species of Psettoidei with further dissections would substantially contribute towards determining if the recessus orbitalis is synapomorphic for the Pleuronectiformes.

\section{Acknowledgements}

MAC obtained specimens and conducted dissections during a 2018-2019 Fulbright Scholar Award (Fulbright Taiwan). The authors would like to acknowledge N. Schnell and S. Iglesias (MNHN, Station Marine de Concarneau, France) for help in the sampling and examining sole specimens, the anonymous reviewers and the Editor (N. K. Lujan) whose comments improved the manuscript. This work was supported, in part, by research grant from the Ministry of Science and Technology, Taiwan (MOST 107-2119-M-001-048 [SCSMART]). 


\section{References}

Burgin, T. (1989). The oral jaw apparatus of the Indian Halibut, Psettodes erumei (Bloch and Schneider, 1801) (Teleostei; Pleuronectiformes) — a formal description with functional considerations. 35, 463-466.

Campbell, M. A., Chen, W.-J., \& López, J. A. (2013). Are flatfishes (Pleuronectiformes) monophyletic? Molecular Phylogenetics and Evolution, 69, 664-673. https://doi.org/10.1016/j.ympev.2013.07.011

Campbell, M.A., Chanet, B., Chen, J.-N., Lee, M.-Y., \& Chen, W.-J. (2019) Origins and interrelationships of the Pleuronectoidei: Molecular and morphological analysis of living and fossil taxa. Zoologica Scripta, 48, 640-656. https://doi.org/10.1111/zsc.12372

Chabanaud, P. (1937). Les téléostéens dyssymétriques du Mokkatam Inférieur de Tourah. Mémoires présentés à l'Institut d'Égypte, 31, 1-122.

Chanet, B., Mondejar-Fernandez, J., \& Lecointre, G. (2020). Flatfishes interrelationships revisited based on anatomical characters. Cybium, 44, 9-18. https://doi.org/10.26028/cybium/2020-441-002

Chapleau, F. (1993). Pleuronectiform relationships: a cladistic reassessment. Bulletin of Marine Science, 52, 516-540.

Cole, F. J., \& Johnstone, J. (1902). Pleuronectes (The Plaice). Memoirs of the Liverpool Marine Biology Committee, 8, 1-252.

Holt, E. W. L. (1894). Studies in teleostean morphology from the Marine Laboratory at Cleethorpes. Proceedings of the Zoological Society of London., 1894, 413-446.

Hoshino, K. (2001). Monophyly of the Citharidae (Pleuronectoidei: Pleuronectiformes: Teleostei) with considerations of pleuronectid phylogeny. Ichthyological Research, 48, 391-404. https://doi.org/10.1007/s10228-001-8163-0

Munroe, T. A. (2005). Systematic Diversity of the Pleuronectiformes. In Flatfishes: Biology and Eploitation (Gibson, R. N., ed), pp. 10-41 Oxford, UK: Blackwell.

Norman, J. R. (1934). A systematic monograph of the flatfishes (Hetersomata), Vol. 2. Psettodidae, Bothidae, Pleuronectidae., 1934.

Paradis, E., \& Schliep, K. (2018). Ape 5.0: An environment for modern phylogenetics and evolutionary analyses in R. Bioinformatics, 35, 526-528. https://doi.org/10.1093/bioinformatics/bty633 


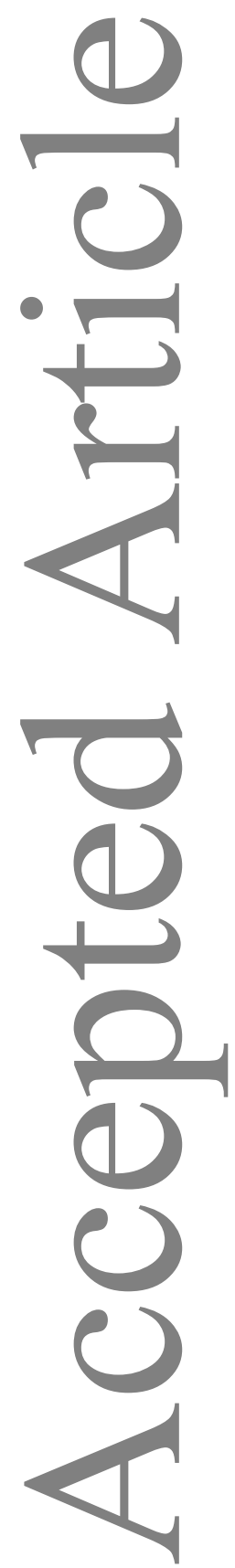

This article is protected by copyright. All rights reserved. 
Table 1 Pleuronectiform taxa for which the presence of the recessus orbitalis has been evaluated through dissection. The presence is indicated as well as the reference. Classification follows Campbell et al. (2019).

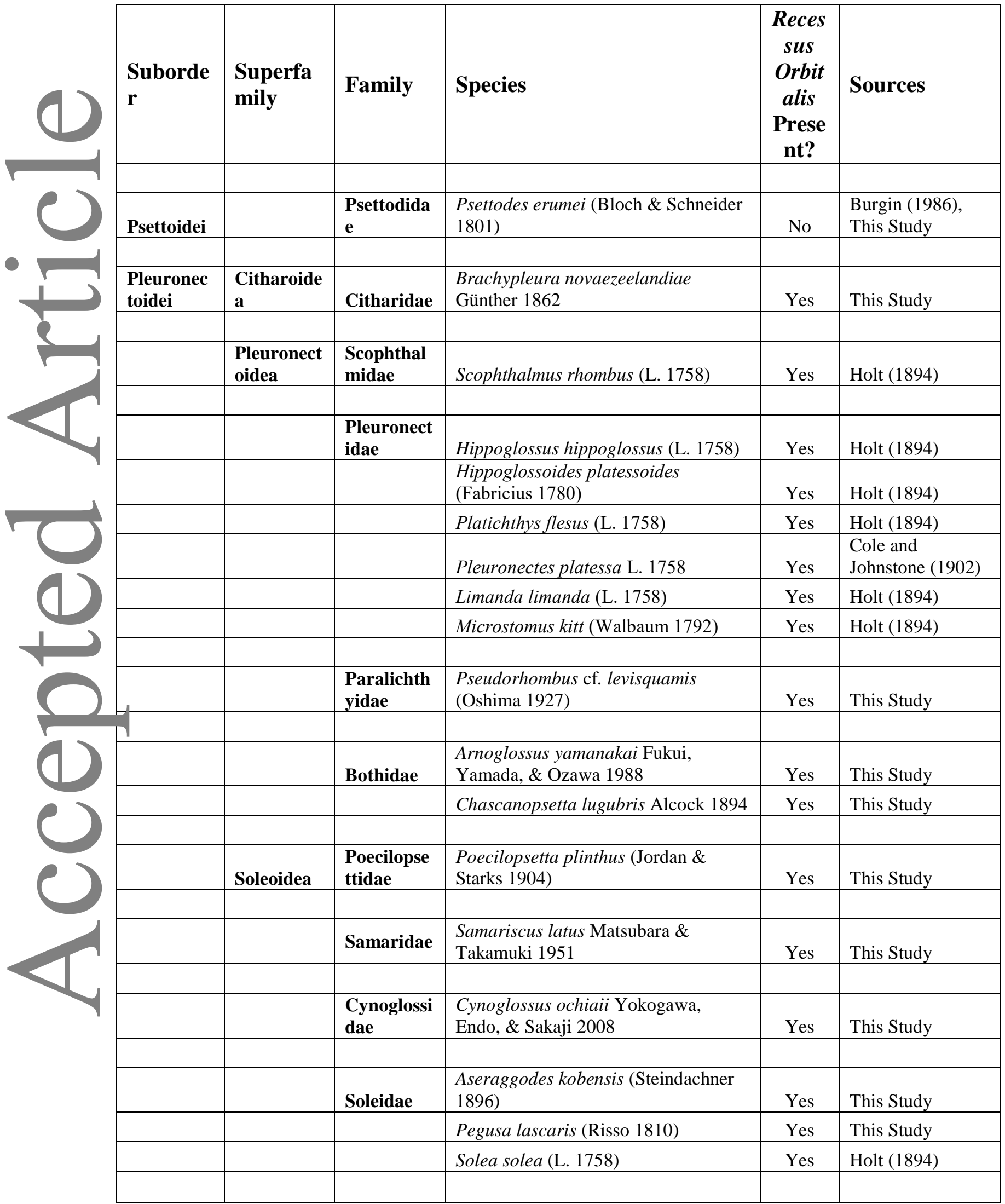


Figure 1 (A) Example of a flatfish (Bothidae, left-eyed species) utilizing the recessus orbitalis to protrude its eyes while stationary on the substrate. Photo by M. Campbell. (B) The recessus orbitalis in a plaice, Pleuronectes platessa, (right-eyed species, modified from Holt 1894, pl. XXX, fig. 5). (C) Ocular side of a dissected left-eyed Psettodes erumei (NTUM 16050, $40.0 \mathrm{~cm} \mathrm{SL}$ ). (D) Ocular side of a dissected right-eyed Psettodes erumei (NTUM NTUM17077, $39.5 \mathrm{~cm} \mathrm{SL).} \mathrm{(E)} \mathrm{Ocular} \mathrm{side} \mathrm{of} \mathrm{a} \mathrm{dissected} \mathrm{Pseudorhombus} \mathrm{cf.} \mathrm{levisquamis}$ (left-eyed species, NTUM 16051, $23.0 \mathrm{~cm}$ SL). (F) Ocular side of a dissected Brachypleura novaezeelandiae (right-eyed species, NTUM17076, $7.6 \mathrm{~cm}$ SL). Legend: 1. Adductor mandibulae muscle; 2. Non-migrating eye; 3. Migrating eye; 4. Recessus orbitalis; 5. Removed skin.

Figure 2 Distribution of the recessus orbitalis across families of flatfishes (Pleuronectiformes) accompanied by ancestral character estimation of this character conducted at the family-level. Pleuronectoid family relationships follow Campbell et al. (2019). Confirmed absence of the recessus orbitalis is indicated by white circle at a tip, confirmed presence by a black filled circle, and unknown by a question mark (?) in a circle. If the presence of the recessus orbitalis was deduced from photographs, it is indicated by an asterisk "*” following the family name. The probability of the recessus orbitalis in nodes of the tree is proportional to the amount of black area within each circle. 


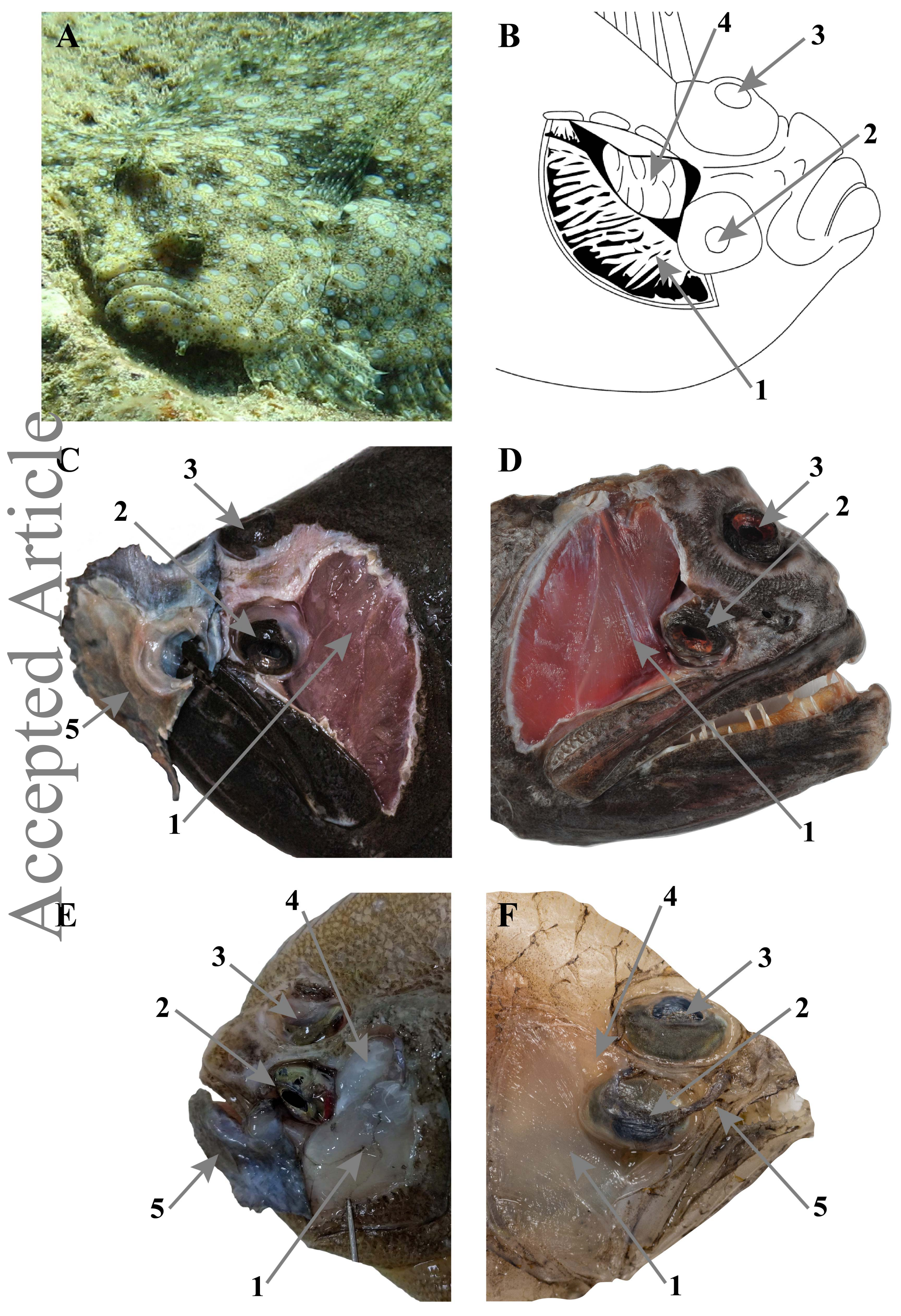


Centropomidae

O Psettodidae

- Citharidae

- Scophthalmidae

Y)

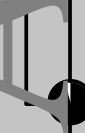

Pleuronectidae

Cyclopsettidae*

Bothidae

(3) Achiropsettidae

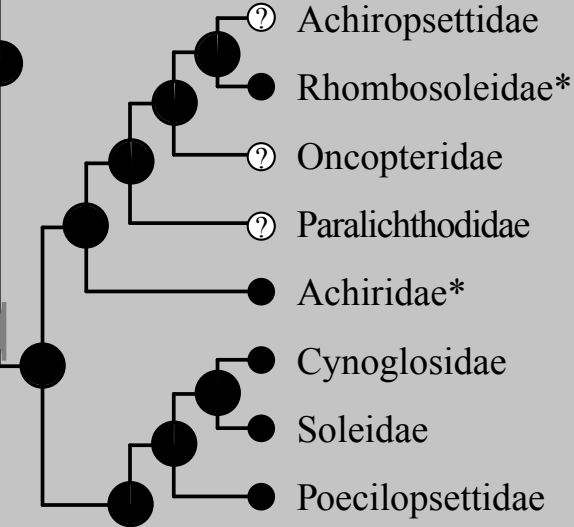

This article is protected by copyright. All rights reserved. Samaridae

\section{Pleuronectoidei}

(?) No Data 